\title{
Bitcoin ve Kripto Paralar Hakkında Çוkan Haberlerin Bitcoin Fiyatları Üzerine Etkisi ${ }^{1}$
}

\author{
Türker TEKER ${ }^{2}$ - Ayșen KONUȘKAN ${ }^{3}$ \\ Vesile ÖMÜRBEK ${ }^{4}$ - İsmail BEKÇ⿻i ${ }^{5}$
}

Makale Gönderim Tarihi: 20.05.2019

Makale Kabul Tarihi: 16.03.2020

\section{Öz}

Bitcoin, kripto paralar içinde, günlük ișlem hacmi en yüksek olan para birimi olarak ön plana çıkmaktadır. Bu çalıșmada, Bitcoin, ya da tüm kripto paralar hakkında küresel düzeyde yayınlanmıș olan olumlu ve olumsuz haberlerin, bitcoin gün sonu kapanıș fiyatları, gün içi bitcoin en yüksek fiyat seviyesi ve günlük bitcoin ișlem hacimlerinde yarattığı değișim incelenmiștir. Çalıșmada Mayıs 2018-Aralık 2018 arasında yahoofinance.com ve Bloomberg.com web sayfalarında bitcoin ve kripto paralar ile ilgili yayınlanan haberler değerlendirmeye alınmıștır. Elde edilen bulgular, kripto paralar ve bitcoin ile ilgili olumlu ve olumsuz çıkan haberlerin, bitcoin fiyatları ve ișlem hacimleri üzerinde anlamlı bir farklılığa yol açmadığını ortaya koymaktadır.

Anahtar Kelimeler: Bitcoin, Kripto Para, Mann-Whitney U

Jel Kodları: G0 ,F1, F3

"Bu çalıșma 18-20 Nisan 2019 tarihinde İzmir Demokrasi Üniversitesi IÏBF tarafından düzenlenen 4.Lisansüstü İșletme Öğrencileri Sempozyumunda sözlü olarak sunulmuș ve gerekli düzeltmeler yapılmıștır"

2 Arș. Gör., Süleyman Demirel Üniversitesi Bankacılık ve Finans Bölümü, turkerteker@sdu.edu.tr, Orcid ID: 0000-0002-4692-3439

3 Doktora Öğrencisi, Süleyman Demirel Üniversitesi İșletme Bölümü Muhasebe ve Finansal Yönetim, aysen.konuskan45@gmail.com, Orcid ID: 0000-0002-3475-5482

4 Doç. Dr., Süleyman Demirel Üniversitesi İșletme Bölümü Muhasebe ve Finans Anabilim Dalı, vesileomurbek@sdu.edu.tr, Orcid ID: 0000-0001-8647-1708

5 Prof. Dr., Süleyman Demirel Üniversitesi İșletme Bölümü Muhasebe ve Finans Anabilim Dalı, ismailbekci@sdu.edu.tr, Orcid ID: 0000-0002-9861-737X 


\section{The Effect of News About Bitcoin and Crypto Coins on Bitcoin Prices}

\section{Abstract}

Bitcoin stands out as which is most daily trade cryptocurrency in the market. In this study, we have examined the effects of all negative or positive news about bitcoin on changes of daily closing price, daily highest price and daily trading volume of bitcoin. News about bitcoin and cryptocurrencies published on yahoofinance.com and Bloomberg. com web pages between May 2018 and December 2018 were evaluated. The results of the study show that positive and negative news about crypto currencies and bitcoin do not cause a significant difference on bitcoin prices and transaction volumes.

Keywords: Bitcoin, Crypto Money, Mann- Whitney U JEL Codes: G0,F1,F3

\section{Giriș}

Teknoloji kullanımının giderek artı̆ı̆ı, internet kullanımının maksimum seviyeye ulaștığı günümüzde, insanlar ilk çağlarda edinmiș oldukları tüm alıșkanlıklar ve günlük hayatlarını devam ettirmek için gereksinim duydukları tüm faaliyetleri, zamandan ve mekandan bağımsız olarak, olabildiğince hızlı, güvenli ve sonuca ulașabilecekleri șekilde yapmayı amaçlanmaktadır. Haberleșme, yeme-içme, alıșveriș, bilgiye ulașma gibi birçok konuda teknoloji, insanlara maksimum hız ve bulunduğu yerden ișlem yapma imkanı tanımaktadır. Kripto para tarihi incelendiğinde 1983 yılında David Chaum tarafindan tasarlanan e-cash (wikipedia, 2018) ile bu alandaki ilk hamlenin yapıldığı görülse de 2008 yılında Satoshi Nakatomo kod adını kullanan bir șahıs ya da grup tarafından ilk deneysel temelleri atılan Bitcoin'in ortaya çıkmasıyla bugün bildiğimiz anlamdaki ilk kripto para üretilmiș, sonrasında farklı özelliklerde birçok kripto para icat edilmiștir (webrazzi, 2016). Kripto paralar, yatırım yapılabilir olması, birikim aracı olması, alıșveriș imkanı tanıması, saklama kolaylığına sahip olması gibi birçok yönüyle teknolojinin getirmiș olduğu bir çok imkanı bünyesinde barındırmaktadır.

Bu çalıșmada kripto paralar içinde payı ve bilinirliği en yüksek olan Bitcoin, detaylı incelemeye alınarak, Bitcoin hakkında çıkan ve ses getiren olumlu veya olumsuz haberler ile, kripto paraların geneliyle ilgili 
çıkan olumlu veya olumsuz haberlerin Bitcoin fiyatlarında meydana getirdiği etki araștırılmaktadır.

\subsection{Kripto Para}

Kripto Para, kriptografinin belirli ilkeleri ile mümkün hale getirilen bir süreçle, dijital bilgi alıșveriși amacıyla tasarlanmıș, ișlemleri güvenli hale getirmek amacıyla șifreleme kullanılan bir para değișim aracıdır (Graydon, 2014).

Kripto paralar, merkezi olmayan kripto sistemlerde, kamuya açık ve herkesin bildiği yöntemlerle sistemin kuruluș așamasında belirlenmiș olan miktarda üretilirler. Geleneksel para sistemlerinde hükümetler, gerekli durumlarda merkez bankaları vasıtası ile para ihraç edebilirler. Ancak, hükümetler veya șirketler kripto para üretimi yapamazlar. Dolașımda bulunacak kripto para miktarı ve para arzının șekli ve zamanlaması, kripto-sistem kurulurken belirlenmektedir (Çarkacıoğlu, 2016:9).

Kripto para denildiğinde dünya genelinde ilk olarak akla Bitcoin gelmektedir. Ancak borsalarda ișlem gören, her geçen gün yatırımcısı ve meraklısı artan birçok kripto para bulunmaktadır.

Bitcoin, Ripple, Ethereum gibi kripto paraların tanınırlığı ve ișlem hacimleri yüksek olsa da farklı isim ve ölçekte çok sayıda kripto para türü bulunmaktadır (investing.com). Bitcoin, Ripple, Ethereum, Eos, Stellar, Tether gibi sayıları 2500'e yaklașan kripto para çeșidi mevcuttur (investing.com).

\subsection{Bitcoin}

Bitcoin, resmi ya da özel herhangi bir kurumun ihracını gerçekleștirmediği ve yine karșllık olarak özel ya da resmi herhangi bir kurum ve kuruluș tarafından güvence verilmeyen bir sanal para birimidir (Sönmez, 2014:8).

Bitcoin bir kripto para birimi olmasının yanı sıra, piyasa kapitalizasyonu, ișlem sayısı, kullanıcı sayısı kriterler açısından bakıldığında alanında öncü olan ve tanınırlığı en fazla olan kripto para birimidir (Gültekin ve Bulut, 2016:89). Bu nedenle kripto para denildiğinde ilk akla gelen, fiyatı yakından takip edilen Bitcoin ön plana çıkmaktadır.

Bitcoin, ișleyiș açısından Dolar, Euro gibi para birimleri ile aynı mantığa sahiptir. Bașka bir para birimi ile bitcoin alım ve satımı yapılabilir, kabul eden ișyerlerinde bitcoin karșılığında mal ve hizmet alım satımı yapılabilir. Birçok e-cüzdan uygulaması platformuna da dahil olan 
Bitcoin, açık kaynak kod aracılığı ile özel istemci sistemlerinin geliștirilmesine olanak sağlamaktadır (Khalilov, Gündebahar ve Kurtulmușlar, 2017).

Bitcoin'i devlet destekli para birimlerinden ayıran özelliklerden bazıları; (coingundem.com)

- Merkezi olmaması

- Hesap açmanın kolay olması

- Anonim olması

- Tamamen șeffaf olması

- İșlem ücretlerinin çok düșük olması

- Hızlı olması

\subsection{Bitcoin Fiyatlarının Seyri}

Grafikte, çalıșmaya dahil edilen Mayıs 2018-Aralık 2018 dönemine ait Bitcoin fiyatının seyrine yer verilmiștir.

Grafik 1. Bitcoin Fiyatları 2018

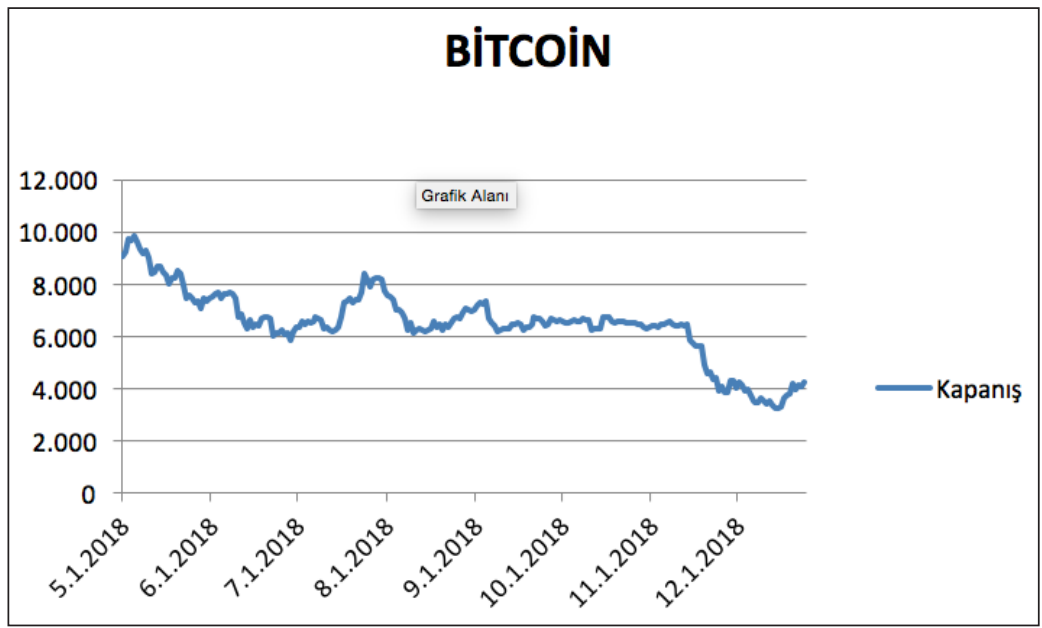

Kaynak: yahoofinance.com verilerinden yararlanılarak hazırlanmıștır.

Her geçen gün bilinirliğini ve kullanım alanları artan Bitcoin'in fiyatı, geniș aralıklarda dalgalanmalar yașamaktadır. 19.056 dolar ile en yüksek seviyesine 2017 Aralık ayında ulașan Bitcoin fiyatı yılsonuna gelindiğinde ise 3500 dolar seviyelerine kadar gerilemiștir. 


\section{Literatür Taraması}

Literatürde Bitcoin hakkında yapılan haberlerin Bitcoin fiyatları üzerinde yarattığı etki ile ilgili herhangi bir çalıșmaya rastlanmamıștır. Bu yönüyle çalıșmanın özgün bir çalıșma olacağı düșünülmektedir. Literatür incelemesinde, Bitcoin'in diğer para birimleri ve ekonomik değișkenler ile aralarındaki ilișkiyi inceleyen çalıșmalara yer verilmiștir.

Güleç, (2018) kripto para birimlerinin, döviz, emtialar, hisse senetleri ve faiz oranları ile ilișkisini ölçmeyi amaçlayan çalıșmasında Mart 2012-Mayıs 2018 dönemi arasında elde edilen aylık veriler kullanıImıștır. Analiz yöntemi olarak Johansen Eșbütünleșme Analizi ve Granger Nedensellik Analizi'nin tercih edildiği çalıșmada, Bitcoin fiyatları ile faiz oranları arasında uzun dönemde anlamlı bir ilișki olduğu ortaya konmuștur. Etki-Tepki analizlerinde faize en yüksek reaksiyonu Bitcoin'in verdiği belirlenmiș ve Bitcoin'in Faizin sebebi olduğu Granger Nedensellik Analizi ile belirlenmiștir.

İçellioğlu ve Öztürk çalıșmalarında (2018), Bitcoin fiyatları ile bazı döviz kurları arasındaki kısa dönemli ilișkiyi belirlemeye çalıșmıșlardır. 2013 ve 2017 yılları arasındaki, Amerikan Doları (USD), Euro, Japon Yeni (JPY), İngiliz Pound'u (GBP) ve Çin Yuanı (CNY) fiyatları incelenmiștir. Yapılan Eșbütünleșme analizi sonucunda, adı geçen döviz kurları ile Bitcoin fiyatları arasında anlamlı bir ilișkiye rastlanmamıștır.

Öget ve Kanat (2018) Bitcoin fiyatları ile Türkiye ve G7 ülkelerinin borsa endeksleri arasındaki nedensellik ilișkisini inceledikleri çalıșmada, 2013-2018 arası günlük verileri kullanmıșıı. Çalıșmada yöntem olarak Granger Nedensellik Analizi ve Vektör Hata Düzeltme Modeli (VECM) kullanılmıștır. Çalıșma sonunda, Bitcoin ile ülkelerin borsa endeksleri arasında herhangi bir uzun dönemli ilișkiye rastlanmamıștır. Kısa dönemli incelemede ise İngiltere borsasının Bitcoin'in sebebi olduğu belirlenmiștir. Ek olarak Bitcoin'in de S\&P500 ve Kanada borsasının (STSX) sebebi olduğu sonucuna ulașılmıștır.

Koçoğlu, Cevik ve Tanrıöven, (2016) Bitcoin piyasasının uluslararası anlamda irdelendiği, gelișimi ve fiyatlandırma sistemlerinin analiz edildiği çalıșmada, Bitcoin piyasasının ișleyiși ile ilgili bilgilere de yer vermiștir. Çalıșmada elde edilen verilere göre Bitcoin fiyatlarının yatııım araçlarının birçoğuyla ters yönlü ilișki içerisinde olması, yatıım çeșitliliği açısından olumlu olsa da oynaklığın yüksek olması sebebiyle spekülatif 
hamlelere maruz kalabilecek bir finansal araç olduğunu ortaya koymușlardır.

\section{Tasarım ve Yöntem}

Bu çalıșmanın amacı, kripto paralar ve Bitcoin ile ilgili küresel düzeyde yayınlanmıș olan olumlu ve olumsuz haberlerin bitcoin fiyatlarında istatistiksel olarak anlamlı bir farklılık meydana getirip getirmediğini ortaya koymaktır. Analizde Mayıs 2018-Aralık 2018 tarihleri arasında yahoofinance.com ve Bloomberg.com gibi tüm dünyadaki yatırımcıların takip ettiği finans sitelerinden elde edilen 40 haberin yayınlandığı ișlem günlerine yer verilmiștir. Yayınlanan haberlerin ișlem saatleri içerisinde olması durumunda o günün seans sonu verileri analize dahil edilirken, piyasalar kapalı iken yayınlanan haberler için akabindeki ilk seans verileri analize dahil edilmiștir.

Bu çalıșmada, yayınlanan haberlerin fiyatlar üzerinde yarattığı ilk tepkinin ölçülmesi esas hedef olarak belirlenmiștir. Herhangi bir para birimi ya da finansal varlık hakkında dünya çapında yayınlanan olumlu ya da olumsuz haberlerin fiyatlar üzerindeki etkisi çok uzun süre boyunca devam edebilmektedir. Bu süre haberin yankılanma gücü ile orantılı olarak artabilmektedir. Farklı bir çalıșmada bu durum göz önünde bulundurularak haftalık ya da aylık ortalamalar kullanılarak etkinin arındırılma sürecini ölçen bir uygulama (event study) yapılabilir. Bu çalıșmada ise kripto paraların, çıkan olumlu ya da olumsuz haberlere ne kadar duyarlı olduğunun tespiti amacıyla ilk gelen piyasa tepkilerini karșılaștırmak amaçlanmıștır.

Çalıșmada kullanılan Bitcoin fiyatlarına dair veriler yahoofinance.com'dan elde edilmiștir. Çalıșmada, olumlu ve olumsuz haberlerin bitcoin fiyatlarında istatistiksel olarak anlamlı bir farklılığa neden olup olmadığının belirlenmesi amacıyla 3 kriter belirlenmiștir:

Gün Sonu Kapanıșı: Gün sonu Bitcoin fiyatlarındaki seviye.

Gün İçi En Yüksek Değer: Bitcoin fiyatlarının gün içinde ulașmıș olduğu en yüksek fiyat

Günlük İșlem Hacmi: Gün içi toplam Bitcoin ișlem hacmi

Belirlenen 40 adet olumlu ve olumsuz haberin yayınlandığı günler belirlenerek, o günlere ait Bitcoin fiyat verileri düzenlenmiștir. İstatistiksel olarak anlamlı hale getirebilmek adına, olumsuz haberlere "1", olumlu haberlere "2" rakamı verilerek bu haberlerin çıktığı günler ișaretlenmiștir 
Verilerin normal dağılıma sahip olup olmadığının belirlenmesi amacıyla veriler ilk olarak Shapiro-Wilk testine tabi tutulmuștur. Analiz sonuçlarına göre verilerin normal dağılıma sahip olmadığı belirlenmiș olup, uygulamaya parametrik olmayan testler ile devam edilmesi gerektiğine karar verilmiștir (Demirgil, 2016).

\section{Tablo 1. Normallik Testi}

\begin{tabular}{|l|c|c|c|}
\hline \multirow{2}{*}{} & \multicolumn{3}{|c|}{ Shapiro-Wilk } \\
\cline { 2 - 4 } & Statistic & $\mathrm{df}$ & Sig. \\
\hline Kapanıș &, 894 & 40 &, 001 \\
\hline En Yüksek Değer &, 892 & 40 &, 001 \\
\hline Hacim &, 866 & 40 &, 000 \\
\hline
\end{tabular}

Yayınlanmıș olan olumlu ve olumsuz haberlerin, yukarıda belirlenen 3 kriter nezdinde Bitcoin fiyatlarında istatistiksel olarak anlamlı bir farklılık yaratıp yaratmadığını belirlemek amacıyla parametrik olmayan testlere uygun olarak Mann-Whitney $U$ testi yapılmasına karar verilmiștir. Buna göre:

$\mathbf{H}_{\mathbf{l}}$ : Bitcoin kapanıș fiyatlarının dağılımı, Bitcoin ve kripto paralar hakkında olumsuz ve olumlu haber yayınlanan günlerde benzerlik gösterir.

$\mathbf{H}_{2}$ : Bitcoin fiyatlarındaki gün içi en yüksek değer, Bitcoin ve kripto paralar hakkında olumsuz ve olumlu haber yayınlanan günlerde benzerlik gösterir.

$\mathbf{H}_{3}$ : Bitcoin ișlem hacmi, Bitcoin ve kripto paralar hakkında olumsuz ve olumlu haber yayınlanan günlerde benzerlik gösterir.

\section{Bulgular ve Tartıșma}

Çalıșmada SPSS (Versiyon 21) yardımıyla analiz yapılmıștır. Elde edilen Mann-Whitney $U$ testi sonuçları așağıda sunulmuștur.

\section{Tablo 2. Gün Sonu Kapanıș}

\begin{tabular}{|c|c|c|c|c|c|c|}
\hline $\begin{array}{c}\text { Gün Sonu } \\
\text { Kapanıș }\end{array}$ & $\mathbf{N}$ & Sıra Ortalamaları & Sıra Toplamı & $\mathbf{U}$ & $\mathbf{Z}$ & p (olasılık) \\
\hline 1 & 19 & 21,63 & 411 & 178 & -582 & 0,573 \\
\hline 2 & 21 & 19,48 & 409 & & & \\
\hline
\end{tabular}

Tablo 2'de Bitcoin ve kripto paralar hakkında olumlu ve olumsuz haber çıkan ișlem günlerindeki gün sonu kapanıș fiyatları karșılaștırılmıș- 
tır. P istatistiği \% 95 güven aralığında 0,05 değerinden büyük olduğu için $\mathrm{H}_{0}$ hipotezimiz kabul edilecektir. Analiz sonucunda iki grup arasında istatistiksel olarak anlamlı bir farklılığa rastlanmamıștır ( $p=0,573)$.

Tablo 3. Gün İçi En Yüksek Değer

\begin{tabular}{|c|c|c|c|c|c|c|}
\hline $\begin{array}{c}\text { Gün İçi En } \\
\text { Yüksek Değer }\end{array}$ & N & Sıra Ortalamaları & Sıra Toplamı & U & Z & plolasılık) \\
\cline { 1 - 5 } 1 & 19 & 21 & 399 & 190 & -257 & 0,810 \\
\hline 2 & 21 & 20,05 & 421 & & & \\
\hline
\end{tabular}

Tablo 3'te Bitcoin ve kripto paralar hakkında olumlu ve olumsuz haber çıkan ișlem günlerindeki gün içi en yüksek değerler karșılaștırılmıștır. P istatistiği \% 95 güven aralığında 0,05 değerinden büyük olduğu için $\mathrm{H}_{0}$ hipotezimiz kabul edilecektir. Analiz sonucunda iki grup arasında istatistiksel olarak anlamlı bir farklılığa rastlanmamıștır $(p=0,810)$.

Tablo 4. Günlük İșlem Hacmi

\begin{tabular}{|c|c|c|c|c|c|c|}
\hline $\begin{array}{c}\text { Gün Ị̇i En } \\
\text { Yüksek Değer }\end{array}$ & N & Sıra Ortalamaları & Sıra Toplamı & U & Z & p(olasılık) \\
\cline { 1 - 4 } 1 & 19 & 20,68 & 393 & 196 & -095 & 0,936 \\
\hline 2 & 21 & 20,33 & 427 & & & \\
\hline
\end{tabular}

Tablo 4.'de Bitcoin ve kripto paralar hakkında olumlu ve olumsuz haber çıkan ișlem günlerindeki günlük ișlem hacimleri karșılaștırılmıștır. P istatistiği \% 95 güven aralığında 0,05 değerinden büyük olduğu için $\mathrm{H}_{0}$ hipotezimiz kabul edilecektir. Analiz sonucunda iki grup arasında istatistiksel olarak anlamlı bir farklılığa rastlanmamıștır (p:0,936).

\section{Tablo 5. Hipotez Testleri Sonuç Tablosu}

\begin{tabular}{|l|l|l|}
\hline $\mathrm{H}_{1}$ & $\begin{array}{l}\text { Bitcoin kapanıs fiyatlarının dağılımı, Bitcoin ve kripto paralar hakkında olum- } \\
\text { suz ve olumlu haber yayınlanan günlerde benzerlik gösterir. }\end{array}$ & KABUL \\
\hline $\mathrm{H}_{2}$ & $\begin{array}{l}\text { Bitcoin fiyatlarındaki gün içi en yüksek değer, Bitcoin ve kripto paralar hakkın- } \\
\text { da olumsuz ve olumlu haber yayınlanan günlerde benzerlik gösterir. }\end{array}$ & KABUL \\
\hline $\mathrm{H}_{3}$ & $\begin{array}{l}\text { Bitcoin işlem hacmi, Bitcoin ve kripto paralar hakkında olumsuz ve olumlu haber } \\
\text { yayınlanan günlerde benzerlik gösterir. }\end{array}$ & KABUL \\
\hline
\end{tabular}

\section{Sonuç, Öneriler ve Kısıtlar}

Bitcoin, günden güne popülarite kazanan bir finansal varlık olmasının yanı sıra, 20 bin dolarlık fiyata ulașmasıyla en değerli yatırım araçları arasına girmiștir. Ancak fiyatlarında yașanan keskin dalgalanmalar, her yeni gün bir yatırım kurulușu ya da analistin bitcoin'in geleceğiyle 
ilgili farklı yorumlar yapıyor olması, arkasında herhangi bir ülke ya da bir kurum güvencesi olmaması bitcoin'e temkinli yaklașılması gerektiği yönündeki tezi savunanları doğrulayan gelișmeler arasında yer alıyor. Bu çalıșmada, bitcoin fiyatlarının bitcoin ve diğer kripto paralar hakkında önemli yayın organlarında yer alan haberlerden etkilenip etkilenmediği ile ilgili bir farklılık analizi yapılmıștır.

Olumlu ve olumsuz haberlerin yarattığı etkiyi tespit edebilmek adına, yakın zamanda bitcoin ile ilgili medyada yer alan 19'u olumsuz 21 'i olumlu olmak üzere 40 haber tespit edilmiș ve bitcoin fiyatlarında bu 40 haberin yer aldığı günkü hareketler izlenmiștir. Verilere normallik testi uygulanmıș ve normal dağılım göstermediklerinin belirlenmesinin ardından parametrik olmayan veriler için uygulanan bir test olan MannWhitney U Testi uygulanmıștır. Çalıșmanın sonunda, Bitcoin ve kripto paralar ile ilgili basında yer alan olumlu ve olumsuz haberlerin:

- Günlük ișlem hacminde istatistiksel olarak anlamlı bir farklılık yaratmadığı,

- Gün içi en yüksek değerler açısından anlamlı bir farklılık göstermediği

- Gün sonu kapanıșı açısından anlamlı bir farklılık göstermediği belirlenmiștir.

Bu çalıșmada her geçen gün tanınırlığı, farkındalığı artıș gösteren kripto para dünyasının lokomotifi olan bitcoin'in, gündelik haberlere ne kadar duyarlı olduğu ve bu haberlerin bitcoin fiyatları üzerindeki etkisi temel düzeyde ölçülmeye çalıșılmıștır. Çalıșmada Mayıs 2018-Aralık 2018 arasında kripto paralar hakkında yayınlanmıș haberler incelemeye alınmıștır. İlerleyen süreçte benzer çalıșmalar yapacak ya da mevcut çalıșmaları geliștirmek isteyen araștırmacılar, daha geniș tarih aralıklarında inceleme yaparak daha çok sayıda haber üzerinden analiz yapabilir ya da haberlerin fiyatlar ve hacim üzerindeki etkisini daha geniș bir zaman diliminde inceleyebilirler. Ya da gün içi verilerden yararlanılarak, kripto paralar hakkında çıkan haberlerin seans sırasında fiyatlara verdiği tepkiler incelenebilir. 


\section{KAYNAKÇA}

Coingundem.com. http://www.coingundem.com/bitcoin-nedir Erișim Tarihi: 19.12.2018

Çarkacıoğlu, A. (2016). Kripto Para-Bitcoin. , Araștırma Raporu, SPK Araștırma Dairesi, Ankara.

Demirgil, H. (2016). Ș. Kalaycı içinde, SPSS Uygulamalı Çok Değișkenli İstatistik Teknikleri (8. Baskı b., s. 85-110).

Graydon, C. (2014). https://www.ccn.com/cryptocurrency/ Erișim Tarihi: 12.2018

Güleç, Ö. F. (2018). Bitcoin İle Finansal Göstergeler Arasındaki İlișkinin İncelenmesi. Kırklareli Üniversitesi İktisadi ve İdari Bilimler Fakültesi Dergisi, 18-37.

Gültekin, Y., \& Bulut, Y. (2016). Bitcoin Ekonomisi: Bitcoin Eko-Sisteminden Doğan Yeni Sektörler Ve Analizi. Adnan Menderes Üniversitesi Sosyal Bilimler Enstitüsü Dergisi, 82-92.

Investing.com. https://tr.investing.com/crypto/ Erișim Tarihi 19.12.2018

Khalilov, M. K., Gündebahar, M., \& Kurtulmușlar, İ. (2017). "Bitcoin ile Dünya ve Türkiye'deki Dijital Para Çalıșmaları Üzerine Bir İnceleme. 19. Akademik Bilișim Konferansı.

Koçoğlu, Ș., Çevik, Y. E., \& Tanrı̈ven, C. (2016). Bitcoin Piyasalarının Etkinliği, Likiditesi ve Oynaklığı. İșletme Araștırmaları Dergisi, 77-97.

Öget, E., \& Kanat, E. (2018). Bıtcoin Ille Türkiye Ve G7 Ülke Borsaları Arasındaki Uzun Ve Kısa Dönemli İlișkilerin İncelenmesi. Finans Ekonomi ve Sosyal Araștırmalar Dergisi (FESA), 3(3), 601-614.

Sönmez, A. (2014). Sanal Para Bitcoin. The Turkish Online Journal of Design, Art and Communication, 4(3), 8.

Șarkaya İçellioğlu, C, \& Engin Öztürk, M . (2018). Bitcoin ile Seçili Döviz Kurları Arasındaki İlișkinin Araștırılması: 2013-2017 Dönemi için Johansen Testi ve Granger Nedensellik Testi. Maliye ve Finans Yazıları, 1 (109), 51-70. Retrieved from http:// dergipark.org.tr/mfy/issue/32136/343217

Webrazzi. (2016). https://webrazzi.com/2016/05/27/bitcoinden-zengin-olanlarinlistesi/ Erișim Tarihi 19.12.2018

Wikipedia. (2018). https://tr.wikipedia.org/wiki/Kripto_para Erișim Tarihi 19.12.2018

Yahoo Finance. https://finance.yahoo.com/quote/BTC-USD/history? $\mathrm{p}=$ BTC-USD 